Project presentation

\title{
The new Information Technologies at the Service of Historical and Cultural Heritage and Tourism Promotion
}

\author{
Basma Makhlouf-Shabou \\ Information Science Department, Geneva School of Business Administration, \\ University of Applied Sciences and Arts Western Switzerland \\ Rue de la Tambourine 17, Bât. B, 1227 Carouge, Switzerland \\ basma.makhlouf-shabou@hesge.ch \\ Maria Sokhn \\ University of Applied Sciences and Arts Western Switzerland, \\ HES-SO Valais-Wallis \\ Technopôle 3, 3960 Sierre, Switzerland \\ maria.sokhn@hes-so.ch
}

\begin{abstract}
Summary
City-Zen is an interactive spatio-temporal knowledge-browsing platform that aims to valorise cultural heritages. Considering the explosive growth of information, data and knowledge sharing can ensure valuable interdisciplinary applications. While many organizations propose relevant data sets, they are hardly accessed, analysed and reused because of the formats inconsistency and the inappropriate information browsing and visualization. The goal of the project is to valorise the existing cultural heritage through a citizen centric design platform. Based on information qualities, the use case of this project involves a user willing to discover the history of a region and to embark in a cultural journey in the past. This paper exposes the main functionalities City-zen application and shows how those latest should reach the different user needs. It illustrates how historical and cultural heritage valorisation can take advantage from the advancement of new technologies, multimedia \& mobile and how those technologies should promote tourism services.
\end{abstract}

Key words: Open linked data, cultural heritage, information quality, citizen, tourism services, information services, spatio-temporal browsing, knowledge sharing

\section{Introduction}

Given the complexity of modern life, interest in long-term vacations is a trend that seems to be weakened. Unlike conventional tourist stays and tourist attractions, short-term stays are no longer limited to religious buildings, political buildings or military buildings. Rather, the entire neighbourhoods of tourist 
INFuture2017: Integrating ICT in Society

destinations are now the subject of beautification strategies whose objective is to increase their attractiveness.

Additionally, the cultural heritage is nowadays more and more influenced by the access economy. The access economy is an approach where accessibility is more important that owning. This approach uses is mostly based on mobile technologies and avoid third parties. This terminology arose with the sharing economy advent. Several works were based on this new paradigm to apply it on cultural heritage marketing (Cucchiara, 2017, Rialti, 2016, Wroblewski, 2017).

In our work we believe that increasing the availability of relevant information about cultural and historical heritage could be one of those strategies. We aim to take advantage of digital technologies to promote the cultural heritage. For example, during his stay, or even before arriving to destination, tourist needs to know a lot and every think about the area or the city he wants to visit. Even though citizens (residents) may have valuable information for other citizens who visit their region as tourists, it is barely usable with today's information systems because of the inevitable information resources dispersed. This paper presents the functionalities of City-zen including how this platform proposes to assume the challenge of information quality assessment.

\section{Concrete needs \& user scenario}

In order to describe the goal, we first present a use case scenario. The scenario is seen from three different points of view according to two different potential roles of a citizen within our platforms: 1) tourists and 2) residents.

\section{1) Citizen as a tourist}

Anne, living in Geneva, is visiting the city centre of Sion. When she organized her sightseeing itinerary at home, she searched the web in advance for information about the city. She browsed existing tools and web sites such as tripadvisor, social networks, etc. in order to gather some information about the city. After her arrival at the destination, she decided to have a walk in the city and discover its story and culture. She is standing in front of the white facade of the town hall. She might be interested in a variety of questions regarding the building and the local environment:

- What building is this, when was it built?

- What was the role of this building 50 years / 200 years / 500 years ago (at any other date in the past); did something of interest happen at this place?

- Who is the architect of the building?

- Where are other relevant sights located? How can I get there?

- Are there photos (e.g., from other perspectives or with different scenes in the foreground, etc.) of the gate on the web? 
Anne holds a smart phone, but in order to get information along the lines of the questions above, she has to manually query different sources on the web (and she has to identify these sources first). For some questions, partial support already exists (e.g., spatio-temporal services from Google showing restaurants and hotels on a map), but in most cases, no existing and in particular no integrated solution can be consulted.

\section{2) Citizen as a resident}

Patricia is a resident of Sion since 1954. She knows many anecdotes and stories about her city and she has a lot to tell about places, buildings, people, practices (such as the famous Sion carnival), etc. Patricia has also some inherited age-old objects and objects related to Sion traditions (her first drums when she was 10 years old). With the City-Zen platform, Patricia can be an actor in valorising the cultural and intangible heritage by participating in the knowledge sharing. Patricia can virtually situate her age-old objects on the map using the City-Zen platform and describe them with photos and texts. She can also propose a time slot where she would offer to a citizen (tourist or not) to pass by her house and have a look on these objects.

\section{City-Zen Answering User Needs}

With the City-Zen platform, Anne will be able to directly browse and/or submit queries of different types:

\section{Simple location and spatial queries}

Using the GPS coordinates of her current location, Anne will be able to identify the building she is currently looking at and get access to basic information regarding this building, combined from several data sources on the web. She will search for similar buildings (or buildings that take a similar role) in the vicinity of the current location - e.g., where are the other city gates of Sion located. This query type will also show other relevant information on a map like hotels, restaurants, cinemas, and their most relevant and most recent ratings.

\section{Temporal queries}

On the basis of information from various sources that have been integrated beforehand into the City-Zen platform, Anne will be able to query details of the building's history, if available together with photos from different stages of the building (in case it has been incrementally extended over the years). Moreover, she will also get information on the building's environment at different points in time, and on historic events that took place there. 


\section{Profile-based push notification}

Anne may personalize the City-Zen platform by describing her interests and she may activate the "radar-mode" of City-Zen. This mode pushes notification to Anne whenever she is close to such a point of interest.

The City-Zen platform offers Patricia the object linking service which, in a transparent way for her, links the objects she described to existing information related to that object. As an example, Patricia will be able to link the drum object to the concept of drums explaining that it is an instrument, giving details about its story, and she will also be able to link this object to the traditional art of drumming in the Sion carnival. Two facilities have been used then:

- Heterogeneous multimedia integration: Patricia can access the platform and choose the type of information she wants to share: she may upload an old photo, she could also write an anecdote, she may also upload a video, etc.

- Linked data integration: Patricia pushes the information related to her drums, and the City-Zen platform proposes her to link this description to the concept of drums and to the page web describing the traditions of the drums in Sion. Patricia can ignore this proposition or accept it. In the latter case, the object will be linked to other data already existing objects on the web.

Considering the needs below, City-Zen platform was built on three main modules:

1. Data integrator module responsible of gathering distributed and heterogeneous data. City-Zen makes use of existing approaches to crawl and link accessible or user-generated content;

2. Data analyser module responsible of linking, mapping and cleaning data offering advanced spatio-temporal and personalized queries. City-Zen takes advantage of spatiotemporal information and the web of data approaches.

3. Data visualization module responsible of the adaptive and profile aware knowledge visualization and navigation interfaces. City-Zen takes advantages of existing approaches of Knowledge visualization and valorisation.

\section{Methodological considerations}

A rigorous and systematic literature was realized in order to identify relevant approaches for implementing the previous architecture. A knowledge sharing approach was explored through: Data integration (Heterogeneous databases, Knowledge linking and Data analyser), Temporal multimedia browser (Data and knowledge based queries and profile-context based push notification), and Knowledge visualization (Personalized based knowledge visualization and mobile adapted visualization and navigation). 
Even if each of the described components may require a distinct research and development approach, for the overall methodology, the "Design Science Research Methodology" is used. This process includes the following steps: identifying issues and motivation in order to accurately plan the implementation of our proposed solution.

Defining the goals and objectives: given the issues and motivations defined earlier we infer the objectives of the solution in order to answer the needs and solve the problems. The objective of this step is to define the criteria against which we will be able to evaluate the solution once it is implemented.

Designing \& implementing: designing the system architecture and its components concerns this step. Some elements of the architecture can be implemented just by reusing existing knowledge and technologies, but others, and given the research questions, will need to be developed.

Testing: this step is directly related to the previous and it starts sometimes with the step of design. It concerns the design and development of the proof of concept that will demonstrate the defined use cases.

Evaluating and analysing: this step is concerned with assessing whether the proposed solution meets its defined objectives. Objectives of this step are:

- Technical: to evaluate the accuracy of the results as an objective measure, the flexibility to browse the information space and the performance of the queries.

- Human: to evaluate the usability of the system and the accuracy of the results as a human evaluation given the human mental model for the decision.

- Disseminating: the objectives of this step are to disseminate knowledge through scholarly publications. It will take the form of regular reports and deliverables as well as peer reviewed articles in conferences related to diverse domains: web of data, knowledge visualization, data integration, tourism management and innovation.

\section{City-zen module configuration}

As mentioned, the goal of the project is to valorise the existing cultural heritage through a citizen centric design platform. The use case of this project involves a user willing to discover the history of a region and to embark in a cultural journey in the past. As shown in Figure 1, City-zen addresses (1) the data integration by making use of existing approaches to crawl and link accessible or usergenerated content, (2) a novel approach of data analysis of both assessment methods of data quality and spatio-temporal information, (3) the data visualization by taking advantages of existing approaches of knowledge visualization. 


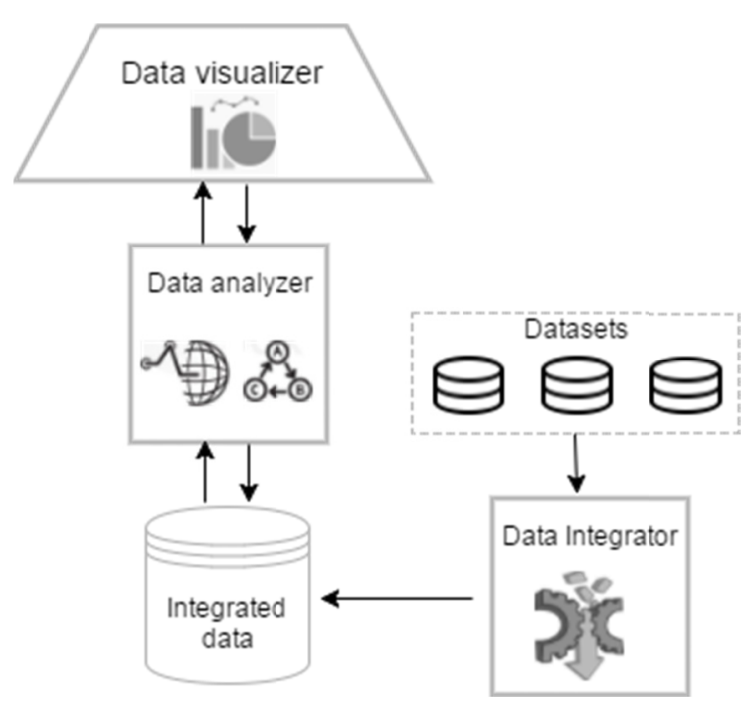

Figure 1. City-zen Architecture

The first part consisted in building the core component of the architecture presented in Figure 1. The platform takes advantages of existing data coming from existing resources. Heterogeneous data collected from different resources have been transformed to a RDF triple store (Figure 2), following a specific data model designed and developed for the needs of City-Zen project. The data model is depicted in Figure 3. For implementing this, different tools have been combined. This aspect is combined with the dimensions of quality applied to historical archives. It focuses mainly on the definition of quality dimensions and the methods that assure their measurement based on specific indicators and variables in the context of historical archives (Makhlouf Shabou, 2011, 2014).

The platform is oriented towards citizens and integrates their data, as they will become available. The platform offers adequate methods and appropriate visual interfaces in order to answer the goal of our project.

\section{Information quality assessment challenge: criteria and metrics}

To enable City-zen platform assessing information quality and information sources, a set of criteria has been identified by using different documentation related to the measurement of quality dimensions applied to electronic records and archives. Two types of information quality criteria were identified: 1) the general information qualities applied on information sources and 2) the specific qualities that could be applied on information content.

The identification of information quality criteria is based on two recent researches: the first is the a doctoral study on the archival appraisal criateria and archival quality metrics (Makhlouf Shabou, 2011) and the second is QADEPs: a 
study on the assessment of digital archives quality metrics (Makhlouf Shabou, Mellifluo, Rey, 2013; Makhlouf Shabou, 2014). Based on those researches, a selection has been established. Two raisons motivate the use of those of information quality criteria in this City-Zen's mobile application: first, for the mobile application, we are going to use electronical data and we need to applied a type of measurement of the information quality; second, this typology of measurement has been already tested in the Canton of Valais (QADEPs, 2013).

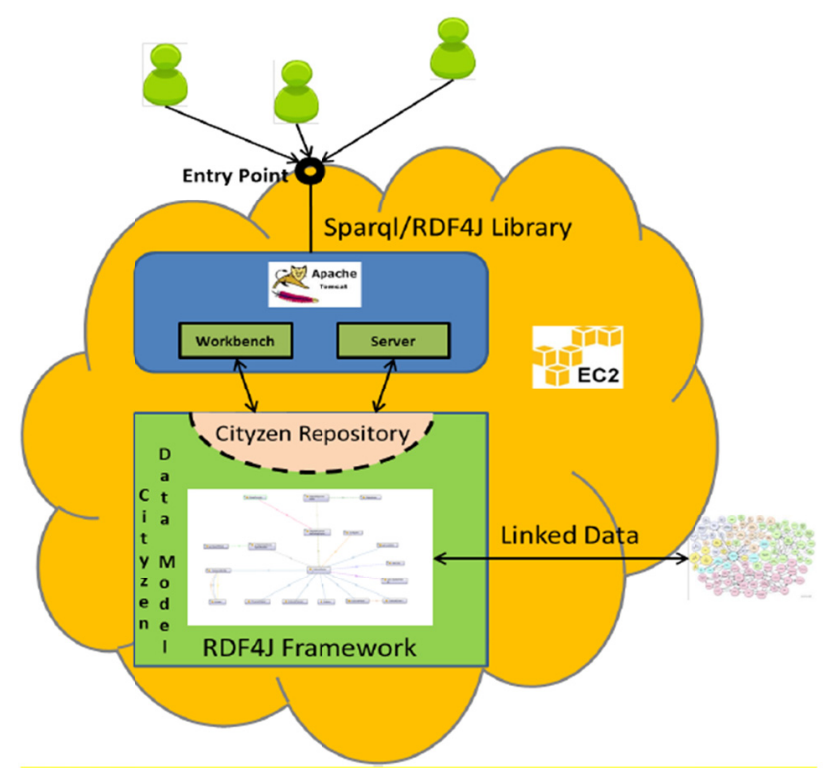

Figure 2. City-Zen RDF triple store design

\section{Information qualities criteria}

City-Zen's application is based on several information quality criteria. Those latest represent the generals and specifics information quality criteria that determine his usability for a tourist when he visits the town of Sion in Valais. Each of the criteria is assessed by a scoring from one to five stars: more the information has a high score, more the information will be trustworthy, exploitable and representative for the tourist.

\section{General information qualities}

Trustworthiness

The tourist will trust this City-Zen's application if this one gathered all the conditions to win his confidence, this means an authentic and reliable information that will make the tourist exploit it by using it. The Trustworthiness "refers to the ability of a document to gain the trust of the user as the preferred supporting facts source. This quality depends on the authenticity and the reliability and the 


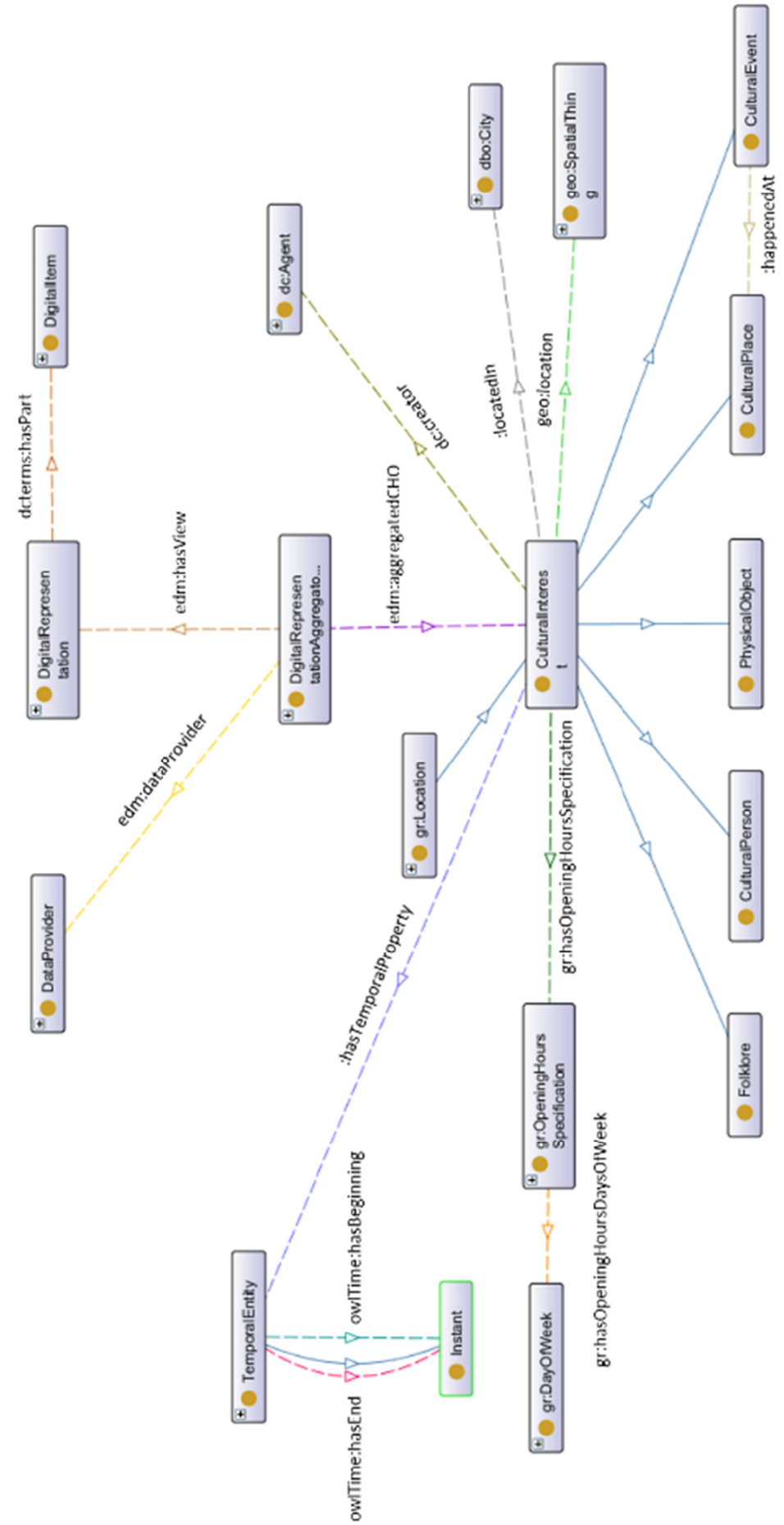

Figure 3. City-Zen data model 
durability of these qualities over time" (Makhlouf Shabou, 2011, p. 115; InterPARES 2, 2013). The tourist will take a document with authentic supporting fact sources that gain his trust over a document with no identifiable source that is difficult to know who the creator is.

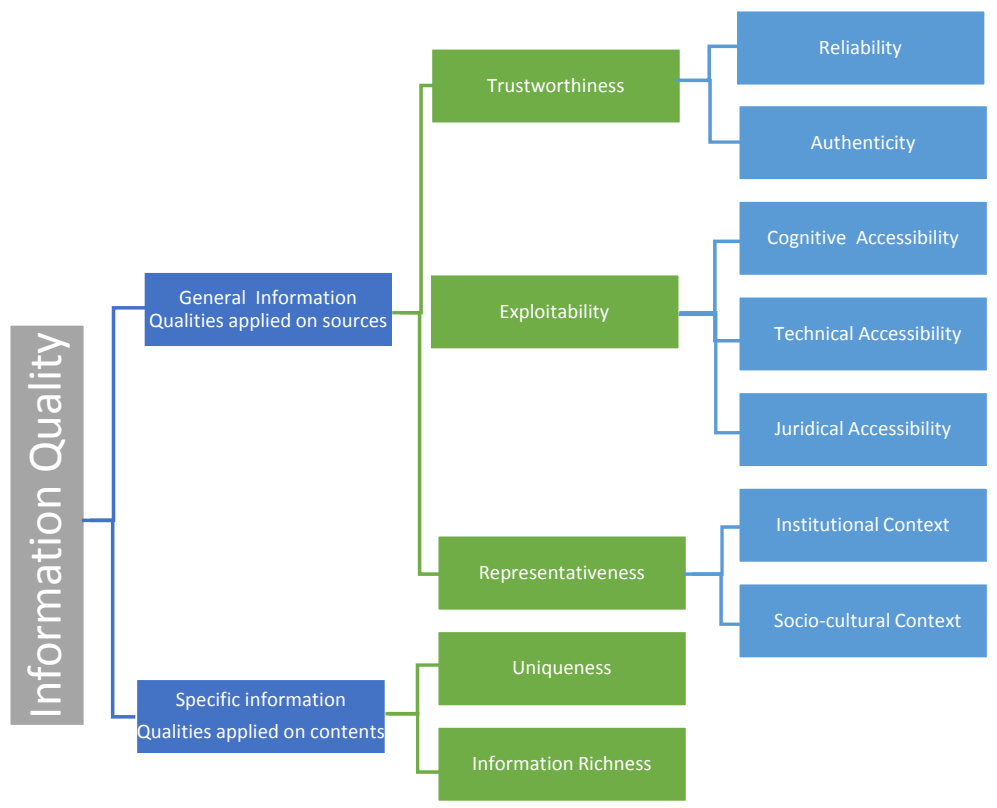

Figure 4. Information Quality Criteria

\section{Exploitability}

The Exploitability is the dimension that "refers to the ease of use of a document, thanks to its location, retrievability, diffusion and interpretability. The exploitability depends on three types of document accessibilities: technical accessibility, including physical and material needed for reading; legal accessibility, including regulatory and administrative environments required for the diffusion of document; and cognitive accessibility that guarantees an adequate comprehension and interpretation of document contents" (ISO 15489-1 :2001; Makhlouf Shabou, 2011)

The information diffused is legally accessible because is author's wright free (only this legal open-access type of information will be put in place for CityZen's application). The information will be easy to comprehend for the tourist but technical information can be also available for the history researchers that wanted to get to know more about Sion. 


\section{$\underline{\text { Representativeness }}$}

This criterion "refers to the capacity of the documents to provide a significant testimony of the institutional context in which they were created. This quality depends on two essential elements: the completeness of testimony; and the representativeness of the socio-cultural context in which these documents were created" (Makhlouf Shabou, 2011).

\section{Specific information qualities}

The specific content quality criteria are the Uniqueness and the Information Richness that City-Zen's application have to provide to give a rare, complete and precise information for the tourist. In this part, we will describe each specific content quality criteria and a specific example of a tourist practice for each criterion. A scoring is going to be set for each criterion.

\section{Uniqueness}

The Uniqueness data quality criterion "describes the fact that each document is related to the others within and outside the fond of which it is a part, and to the creator of the fond by a special relationship, which makes it unique." (AAS Glossary, p.55). In short, this information quality criterion bring attention that there should be no data duplicates reported in the City-Zen's application. Each data will be unique or else the tourist will receive common and a several package of information instead of up-to-date and exclusive information. Asserting uniqueness of the entities within a data set implies that no entity exists more than once within the data set and that there is a key that can be used to uniquely access each entity within the data set. For example, in the City-Zen's application, each information diffused must appear once and be assigned a unique identifier that represents that information across the client applications. The dimension of Uniqueness is characterized by stating that no entity exist more than once within the data set. When there is an expectation of uniqueness, data instances should not be created if there is an existing record of that entity (Loshin, 2006).

\section{Information richness}

With the City-Zen's project, we discuss about the topic of information richness applied to the lowest type of rich information that is the numerical documentation (Kurstedt, 2000). This criteria will be assessed on the basis of the method used by Daft and Lengel (1984), which proposes 5 metrics to consider: 1) the medium (by distance, or face to face); 2) the speed of feedback; 3) Channel (audio, visual; multimedia); 4) source; 5) language.

The highest source in Information Richness is when there is a combination of an official source (impersonal) like information of the Tourism Office in Sion and a citizen's testimony (personal) that's not qualified as an official source. 


\section{Information qualities metrics}

The scoring is based on 3 principals: 1) gradual logic; 2) accumulation of conditions and 3 ) the lowest level is 1 not 0 . Considering those principals, we identified mainly 5 levels. The Figure 5 presents an illustrative examplle of such method applied on information reliability which is a part of trustworthiness.

The detailed description with specification of different information quality levels is available in the table in Annex 1.

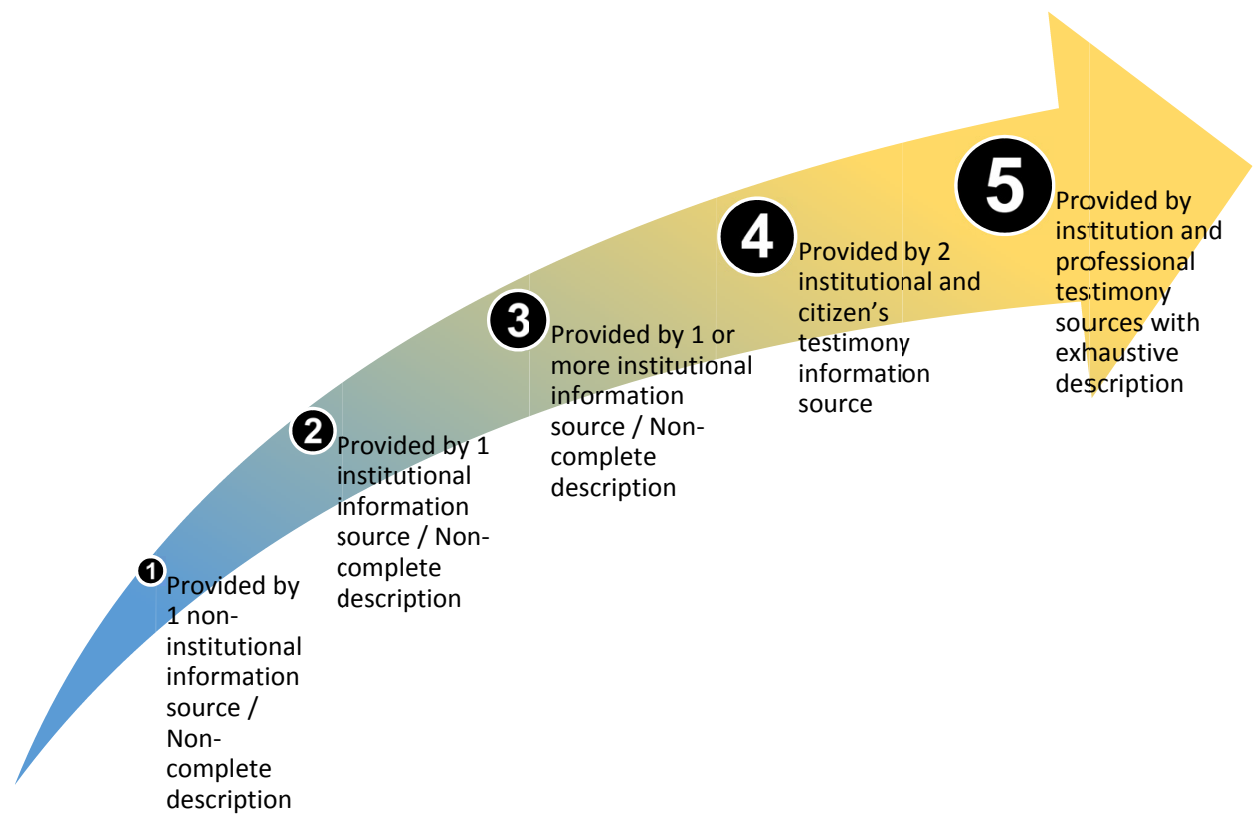

Figure 5. Information reliability: example of applied metrics

\section{Function Display and Visualization}

The City-zen radar mode is depicted in Figure 6. The prototype application uses the user's location and pre-setup filters such as radius and user's interests to visualize in a radar map the interesting places or events around him a video in the annexe show the use of this prototype.

We have designed and implemented à prototype of the interface targeting users with mobile devices. The mobile app provides basic searching and visualization of integrated data.

It allows users to run temporal search for historical multimedia data and navigate in more details about the cultural interests (CI) by reading text information, browse images about the CI over time and if available play videos and audios, and read digitized documents. CIs that have geolocation data, they are visualized on the map (Figure 7). 


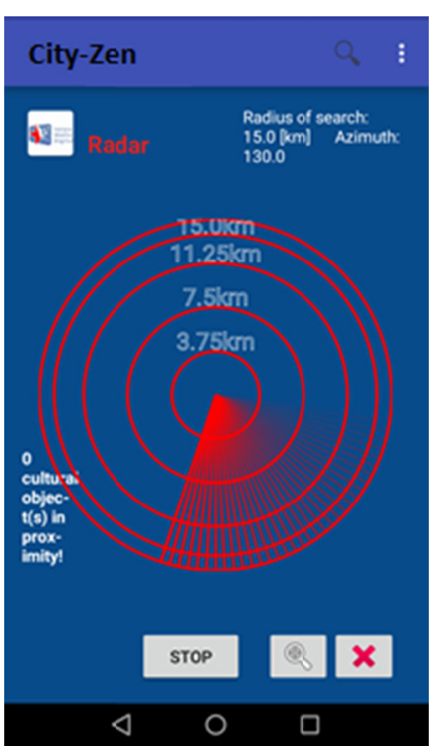

Figure 6. City-Zen radar mode

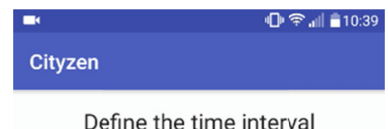

Define the time interval
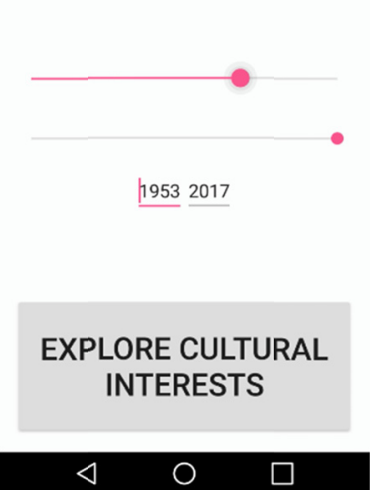
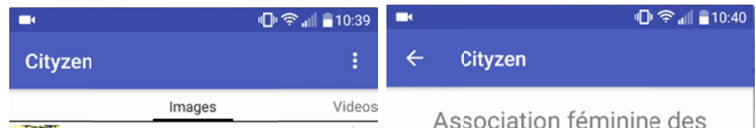

Association féminine des boulangers du Valais romand

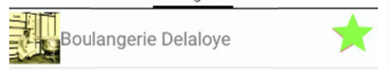
ny 5

17. Association féminine des

12 Association féminine des

Fid Boulangers valaisans

1.J Association féminine des

1. Association féminine des Boulangerie Delaloye

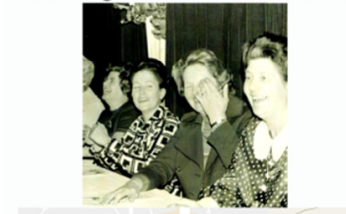

http://www.hevs.ch/datasemlab/cityzen/dataft.. Bas $q u$ de valère $(0$

1. Boulangerie Delaloye

7.e.d. Apprendre à calculer... $=\quad 0 \quad \square$

Un moment de récréation dans une vie
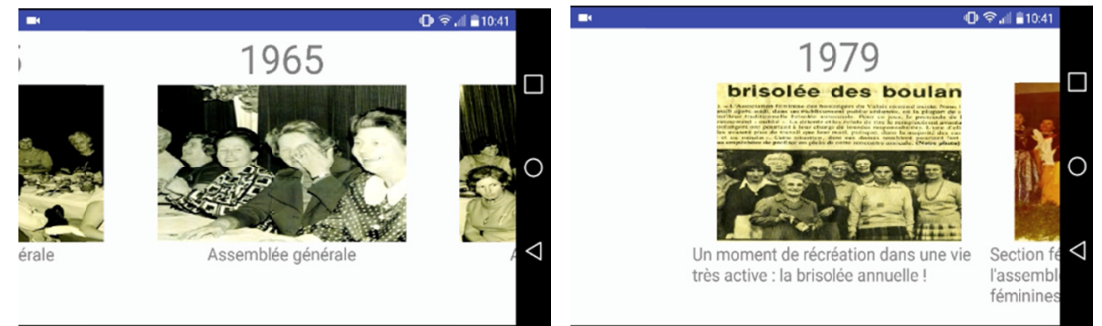

Figure 7. City-Zen mobile app user interfaces: visualization \& navigation 230 


\section{Display of information quality assessment and scoring}

As shown, the requested information is displayed in this app with a specific rank of quality. At this stage of testing, in order to simplify screen view of this service, we reduced the 5 quality levels in 3 levels: the green star corresponds to fourth and fifth, the blue star indicates a medium quality and the grey star refers to the first and second level (Figure 7).

\section{Conclusion}

As explained in this paper, the City-Zen project has proposed an application in a smartphone that offers a resident or a visitor quality information which on one side vulgarize the material heritage (architecture, museum object, historical site, etc.) and immaterial patrimony (culture, oral, culinary traditions). This stage of the project enable the testing of this innovative approach based on open liked data. City-Zen offers through its functionalities an access economy approach that is helpful both for visitors (as they can improve their experience by having full access to aggregated content) and policy makers (as they may promote their cultural heritage through this platform and their city more visible and accessible). On the other hand, several aspects need to be improved such as the section on quality and its metrics to increase the automation of its application. We will also integrate a gamification dimension to motivate citizens to upload their data and share their knowledge. This module will be integrated to the platform in a second phase.

\section{References}

Aberer, Karl. Peer-to-Peer Data Management. Morgan \& Claypool Publishers, 2011.

Barrow, Time. Information Richness Theory. $7^{\text {th }}$ November 2010. http://blog.timebarrow.com/ 2010/11/information-richness/ (19 ${ }^{\text {th }}$ May 2017)

Cazes, G. L'émergence d'un nouveau système vacancier : temporalités et territorialités en mutation. // Hommes et Terres du Nord. $\mathrm{N}^{\circ} 2$ (2001), pp. 63-70.

Cucchiara, R., \& Del Bimbo, A. (2016, September). Bridging the experiential gap in cultural visits with computer vision. In Research and Technologies for Society and Industry Leveraging a better tomorrow (RTSI), 2016 IEEE 2nd International Forum on (pp. 1-4). IEEE.

Cudré-Mauroux, Philippe. Emergent semantics: rethinking interoperability for large scale decentralized information systems. Lausanne : EPFL, 2006.

Cuvelier, Pascal. Anciennes et nouvelles formes de tourisme. Une approche socio-économique. Paris : L'Harmattan, 1998.

Daft, R. L.; Lengel, R. H. Information Richness - a New Approach to Managerial Behavior and Organizational Design. Research in Organizational Behavior. Vol. 6 (April 1983), pp. 191-233.

Instagram. https://instagram.com/ (19 ${ }^{\text {th }}$ May 2017)

International Organization for Standardization. Information et documentation : Records Management. Geneva: ISO 15489-1: 2016.

INTERPARES TRUST. The InterPARES Glossary. Vancouver: International Research on Permanent Authentic Record in Electronic System (InterPARES), Decembre 2001. http://www. interpares.org/book/interpares_book_q_gloss.pdf (19th May 2017)

Kilany R., Sokhn M., Hellani H., Shabani S. (2016) Towards Flexible K-Anonymity. // Knowledge Engineering and Semantic Web. 7th International Conference, KESW 2016 / Ngonga Ngomo Axel-Cyrille; Křemen Petr (eds). Cham: Springer, 2016. 
Lee, Brent. Authenticity, Accuracy and Reliability: Reconciling Arts-related and Archival Littérature. InterPARES 2 Project, septembre 2005. http://www.interpares.org/display_file. cfm?doc=ip2_aar_arts_lee.pdf $\left(19^{\text {th }}\right.$ May 2017)

Loshin, David. Monitoring Data Quality Performance Using Data Quality Metrics. Redwood City: Informatica, novembre 2006. https:/it.ojp.gov/documents/informatica_whitepaper_ monitoring_dq_using_metrics.pdf(19th May 2017)

Makhlouf Shabou, Basma. Measuring the Quality of Records to Improve Institutional Memory. Cincinnati, IEEE International Professional Communication Conference, 17-19th October 2011.

Makhlouf Shabou, Basma. Le projet QADEPs : un outil au service de la pérennisation des archives publiques. // De la préservation à la conservation : stratégies pratiques d'archivage / Hiraux, Françoise; Mirguet, Françoise. Louvain-la-Neuve : Academia l'Harmattan, 2014, pp. 87-98.

Makhlouf Shabou, Basma. Étude sur la définition et la mesure des qualités des archives définitives issues d'une évaluation. Montréal : École de bibliothéconomie et des sciences de l'information. Thèse de doctorat, 2011. http://hdl.handle.net/1866/4955 (19th May 2017)

Makhlouf Shabou, Basma. Digital diplomatics and measurement of electronic public data qualities: What lessons should be learned? // Records Management Journal. Vol. 25 (2015) Issue: 1, pp. 56-77. http://dx.doi.org/10.1108/RMJ-01-2015-0006 (19th May 2017)

Makhlouf Shabou, Basma; Mellifluo, Laure \& Rey, Raphaël (2013). QADEPs: définition et mesure des qualités des archives et documents électroniques. Genève : Haute école de gestion, rapport de recherche, 2013.

Notrehistoire. http://www.notrehistoire.ch/ (19th May 2017)

Pearce-Moses, Richard. A Glossary of Archival and Records Terminology. Chicago: Society of American Archivists, 2005. http://files.archivists.org/pubs/free/SAA-Glossary-2005.pdf (19th May 2017)

Olivieri, Alex Carmine. Improving Automated Fact-Checking Through the Semantic Web. // Web Engineering. ICWE 2016. / Bozzon Alessandro; Cudre-Maroux Philippe; Pautasso Cesare. Cham: Springer, 2016.

Olivieri, Alex Carmine; Sokhn, Maria; Schegg, Roland. Cityzen: a social platform for cultural heritage focused tourism. // Proceedings of the 8th International Conference on Management of Digital EcoSystems. Hendaye, 2016, pp. 129-136.

Rialti, R., Zollo, L., Boccardi, A., \& Marzi, G. (2016). The impact of technologies on visitors' experience personalization: a case study. Micro \& Macro Marketing, 25(2), 251-280.

Rialti, R., Zollo, L., Ciappei, C., \& Laudano, M. (2016, July). Digital cultural heritage marketing: The role of digital technologies in cultural heritage valorization. In 2016 Global Marketing Conference at Hong Kong (pp. 1062-1063)

Sokhn, Maria. Ontology driven framework for multimedia information retrieval in $P 2 P$ network. Computational Engineering, Finance, and Science [cs.CE]. Télécom ParisTech, 2011.

Sokhn, Maria; Makhlouf-Shabou, Basma; Olivieri Alex. Citizens' Platform: an Interdisciplinary Approach for Cultural Heritage Valorisation and Visualization. Tunis, Colloque international sur les bibliothèques et archives à l'ère des Humanités numériques (CIBAHN), 2016.

Tărâță, Cristina. Data quality dimensions - from Accuracy to Uniqueness. 3 March 2015. http://www.performancemagazine.org/data-quality-dimensions-from-accuracy-to-uniqueness/ (19th May 2017)

Tièche, Julien. La mesure des dimensions de la qualité des archives électroniques : apport des textes normatifs en matière d'archivage électronique à long terme. Genève : Haute Ecole de Gestion, travail de Bachelor, 2015. http://doc.rero.ch/record/258018/files/TDB_Tieche_Julien .pdf (19th May 2017)

Valais - Service de la Culture. Vallesiana, le patrimoine numérique du valais. 2017. http://www. vallesiana.ch/ (19th May 2017)

Wroblewski, L. (2017). Culture Management: Strategy and marketing aspects. Logos Verlag Berlin $\mathrm{GmbH}$. 


\section{Annex 1: Information Quality Levels}

\begin{tabular}{|c|c|c|c|c|c|}
\hline \multicolumn{6}{|c|}{ Information Quality Levels } \\
\hline${ }_{\text {Criteria }}^{\mathrm{Sc}}$ & $*$ & $* *$ & $* * *$ & $* * * *$ & $* * * * *$ \\
\hline \multicolumn{6}{|c|}{ General information qualities applied on sources } \\
\hline \multicolumn{6}{|c|}{ Trustworthiness } \\
\hline Reliability & $\begin{array}{l}\text { Provided } \\
\text { by } 1 \text { non- } \\
\text { institu- } \\
\text { tional in- } \\
\text { formation } \\
\text { source } \\
\text { Non-com- } \\
\text { plete de- } \\
\text { scription } \\
\end{array}$ & 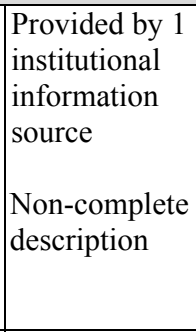 & \begin{tabular}{|l|} 
Provided by 1 \\
or more institu- \\
tional infor- \\
mation source \\
Non-complete \\
description
\end{tabular} & $\begin{array}{l}\text { Provided by } 2 \\
\text { institutional and } \\
\text { citizen's testi- } \\
\text { mony infor- } \\
\text { mation source }\end{array}$ & $\begin{array}{l}\text { Provided by institu- } \\
\text { tion and profes- } \\
\text { sional testimony } \\
\text { sources with ex- } \\
\text { haustive description }\end{array}$ \\
\hline Authenticity & $\begin{array}{l}\text { Provided } \\
\text { by source } \\
\text { non-identi- } \\
\text { fied }\end{array}$ & $\begin{array}{l}\text { Provided by } \\
\text { Citizen's au- } \\
\text { thentic testi- } \\
\text { mony }\end{array}$ & $\begin{array}{l}\text { Provided by } \\
\text { Authentic pro- } \\
\text { fessional testi- } \\
\text { mony }\end{array}$ & $\begin{array}{l}\text { Provided by } \\
\text { multi-source in- } \\
\text { formation }\end{array}$ & $\begin{array}{l}\text { Provided by authen- } \\
\text { tic multi-source in- } \\
\text { formation }\end{array}$ \\
\hline \multicolumn{6}{|c|}{ Exploitability } \\
\hline $\begin{array}{l}\text { Cognitive } \\
\text { Accessibility }\end{array}$ & French & $\begin{array}{l}\text { French/ Ger- } \\
\text { man/Italian }\end{array}$ & $\begin{array}{l}\text { French/ Ger- } \\
\text { man/Italian/ } \\
\text { English/Spanish }\end{array}$ & $\begin{array}{l}\text { Multi-language } \\
\text { (7 languages) }\end{array}$ & $\begin{array}{l}\text { Multi-language } \\
\text { (more than } 10 \text { lan- } \\
\text { guages) }\end{array}$ \\
\hline $\begin{array}{l}\text { Technical } \\
\text { Accessibility }\end{array}$ & $\begin{array}{l}\text { Easy to un- } \\
\text { derstand } \\
\text { for the } \\
\text { French } \\
\text { tourist or } \\
\text { citizen }\end{array}$ & $\begin{array}{l}\text { Easy to under- } \\
\text { stand for the } \\
\text { French/ Ger- } \\
\text { man/ Italian } \\
\text { tourist or citi- } \\
\text { zen }\end{array}$ & $\begin{array}{l}\text { Easy to under- } \\
\text { stand for the } \\
\text { tourist or citi- } \\
\text { zen lambda }\end{array}$ & $\begin{array}{l}\text { All tourists and } \\
\text { citizens can un- } \\
\text { derstand easily }\end{array}$ & $\begin{array}{l}\text { All tourist and citi- } \\
\text { zen can understand } \\
\text { easily }\end{array}$ \\
\hline \begin{tabular}{|l} 
Juridical \\
Accessibility
\end{tabular} & $\begin{array}{l}\text { Infor- } \\
\text { mation is } \\
\text { accessible } \\
\text { but non- } \\
\text { consultable } \\
\text { physically }\end{array}$ & $\begin{array}{l}\text { Information is } \\
\text { accessible but } \\
\text { non-consulta- } \\
\text { ble physically }\end{array}$ & \begin{tabular}{|l} 
Information is \\
accessible but \\
non-consultable \\
physically
\end{tabular} & \begin{tabular}{|l|} 
Information is \\
Open access and \\
can be consulted \\
with a request to \\
the institution \\
with an identifier \\
(download if \\
check-in as user)
\end{tabular} & $\begin{array}{l}\text { Information is Open } \\
\text { access and can be } \\
\text { consulted with a re- } \\
\text { quest to the institu- } \\
\text { tion with an identi- } \\
\text { fier (download if } \\
\text { check-in as user) }\end{array}$ \\
\hline \multicolumn{6}{|c|}{ Representativeness } \\
\hline $\begin{array}{l}\text { Institutional } \\
\text { Context }\end{array}$ & $\begin{array}{l}\text { Recom- } \\
\text { mended by } \\
\text { Office of } \\
\text { Tourism } \\
\text { but infor- } \\
\text { mation not } \\
\text { up to date } \\
\text { (of last } \\
\text { year) }\end{array}$ & $\begin{array}{l}\text { Recom- } \\
\text { mended by } \\
\text { Office of } \\
\text { Tourism but } \\
\text { information } \\
\text { not up to date } \\
\text { (of last year) }\end{array}$ & $\begin{array}{l}\text { Recommended } \\
\text { by Office of } \\
\text { Tourism but in- } \\
\text { formation not } \\
\text { up to date (of } \\
\text { last year) }\end{array}$ & $\begin{array}{l}\text { Recommended } \\
\text { by Office of } \\
\text { Tourism and in- } \\
\text { formation is up } \\
\text { to date }\end{array}$ & $\begin{array}{l}\text { Recommended by } \\
\text { Office of Tourism } \\
\text { and information is } \\
\text { up to date }\end{array}$ \\
\hline
\end{tabular}


INFuture2017: Integrating ICT in Society

\begin{tabular}{|c|c|c|c|c|c|}
\hline $\begin{array}{l}\text { Socio-cultural } \\
\text { Context }\end{array}$ & \begin{tabular}{|l|} 
Infor- \\
mation is \\
not scarce, \\
in a context \\
summary \\
(abstract)
\end{tabular} & $\begin{array}{l}\text { Information is } \\
\text { not scarce, in } \\
\text { a context } \\
\text { summary } \\
\text { (abstract) }\end{array}$ & $\begin{array}{l}\text { Information is } \\
\text { not scarce, in a } \\
\text { context sum- } \\
\text { mary (abstract) }\end{array}$ & $\begin{array}{l}\text { Information } \\
\text { scarce by the ex- } \\
\text { haustiveness of } \\
\text { the context }\end{array}$ & $\begin{array}{l}\text { Information scarce } \\
\text { by the exhaustive- } \\
\text { ness of the context }\end{array}$ \\
\hline \multicolumn{6}{|c|}{ Specific information qualities applied on contents } \\
\hline Uniqueness & \begin{tabular}{|l|} 
- Density \\
of infor- \\
mation, \\
lacks of \\
precision \\
- Abun- \\
dance of \\
format, \\
media, in- \\
formation \\
typology, \\
subject, pe- \\
riod/con- \\
text
\end{tabular} & \begin{tabular}{|l|} 
- Density of \\
information, \\
lacks of preci- \\
sion \\
- Abundance \\
of format, \\
media, infor- \\
mation typol- \\
ogy, subject, \\
period/context
\end{tabular} & $\begin{array}{l}\text { - Selection of } \\
\text { information, } \\
\text { lacks of } \\
\text { precision } \\
\text { - A selection of } \\
\text { format, media, } \\
\text { information ty- } \\
\text { pology, subject, } \\
\text { period / context }\end{array}$ & $\begin{array}{l}\text { - Exclusive In- } \\
\text { formation, pre- } \\
\text { cise and indexed } \\
\text { - Scarcity of } \\
\text { format, media in- } \\
\text { formation typol- } \\
\text { ogy subject, pe- } \\
\text { riod/context. }\end{array}$ & $\begin{array}{l}\text { - Exclusive Infor- } \\
\text { mation, precise and } \\
\text { indexed } \\
\text { - Scarcity of format, } \\
\text { media information } \\
\text { typology subject, } \\
\text { period/context. }\end{array}$ \\
\hline
\end{tabular}

